Berry, Nicole S. 2010. Unsafe motherhood: Mayan maternal mortality and subjectivity in post-war Guatemala. New York and Oxford: Berghahn Books. 268 pp. Hb.: \$85.00. ISBN 9781845457525.

In Unsafe Motherbood anthropologist Nicole Berry looks beneath the surface of the global maternal health campaign and shows how conflicting understandings around birth impede attempts to make pregnancy safer. Interviewing health workers, midwives, and local women and their families in Santa Cruz, Guatemala, Berry finds that the biomedical establishment has wrong assumptions about women's understandings of pregnancy, birth and their own selves. Berry argues that, by making 'modern' alternatives to homebirth uncomfortable, culturally incompatible experiences, these misunderstandings are at the root of the issue.

Central to Berry's theoretical framework is the concept of 'biosocial subjectivities'. Berry uses the term subjectivity to refer 'to someone's own understanding of his or her place in the world' (p. 5). Biosocial, on the other hand, highlights the importance of biological processes in shaping this understanding, and in particular how these processes affect one's social relations. Because 'traditional' birth in Santa Cruz involves not just the pregnant woman and the midwife, but the former's in-laws and husband (with the husband literally holding up his wife), childbirth, Berry argues, is a critical site for 'creating and reinstating' these biosocial subjectivities.

By focusing on the physiology of birth and of the mother (what Berry calls the 'biologicalization of birth') the medical establishment promotes an autonomous understanding of the self. Berry's central contention is that these made-up, autonomous subjectivities clash with people's mutually constituted, relational sub- jectivities. This disagreement, Berry claims, threatens people's identities and makes them reluctant to seek biomedical care.

The major strength of Berry's book has to do with the force of her theoretical framework. Many young anthropologists put forth frameworks that must be awkwardly contorted in order to explain various phenomena. In contrast, Berry's framing of the 'safe motherhood problem' as a clash between different conceptions of subjectivity seamlessly illuminates a wide range of issues. The notion that differences in the ways of thinking are at the core of people's reluctance to adopt better health practices is widely accepted, but the idea is too general to be usefully applied. This is why Berry's work is so valuable: by narrowing the focus from 'different ways of thinking' to 'different ways of seeing oneself', Berry provides a far more applicable model. Of course, understanding how a person sees herself is still not an easy task (for starters, that person is unlikely to have a good idea of it herself). Still, the jump from 'thinking' to 'self-perception' is a significant one, and Berry's book is a testament to the usefulness of this applicable model.

Yet, even if the applicability of Berry's theoretical model is the major strength of the book, at times she goes too far in trying to make every anecdote support her thesis. One of the recurring themes in the book is how 'profoundly uncomfortable' giving birth in hospitals can be for poor Mayans. While Berry offers plenty of constructive examples, she seems to contradict herself at times, for example when asserting that the fact that family members are allowed to be present in the delivery room demonstrates health workers' lack of concern for their patients' dignity. Considering that one of her central points concerns the benefits of communal homebirths, to say that the presence of family members during hospital births is uncomfortable implicates their 
presence during homebirths is uncomfortable as well.

Despite such minor flaws, Unsafe Motherhood is an extremely valuable book that sheds light not only on the obstacles to making motherhood safer, but to improving the health of poor populations in general. By challenging the reader to seek to understand how other people see themselves, their bodies and their biological processes, Berry's book promises to improve how aspiring global health workers think about health and development. Written in clear, simple language, the book should be read by undergraduates in anthropology, sociology and development studies (including economics) all the way to professionals in these fields. Unpretentious but deeply thoughtful, Berry's book provides the field of medical anthropology with an exemplary piece of work.

\section{JAKE COHEN}

Yale University (USA)

\section{Birkenmaier, Anke and Esther Whitfield (eds.) 2011. Havana beyond the ruins: cul- tural mappings after 1989. Durham and London: Duke University Press. 344 pp. Pb.: \$24.95. ISBN 978-0-8223-5052-1.}

This beautifully edited book is a sui generis experiment in exploring the present and imagining the future of Havana beyond its ruins - colonial, capitalist and socialist - by bringing together contributions of Cuban scholars (living inside and outside Cuba) and other nonCuban specialists in various disciplines (architecture, history, literary studies and sociology). Even though anthropologists are absent from this collection, its theoretical and empirical explorations are strongly resonating with a recent upsurge of interest in the anthropology of ruin(ation) (Dawdy 2010), under the influence of Walter Benjamin's unfinished yet brilliant explorations of 19th-century Paris (Benjamin and Tiedemann 1999).

Cuban essayist and writer Antonio José Ponte, in dialogue with W. Benjamin, W.G.
Sebald and G. Simmel, has provided an original interpretation of the relationship between ruins and politics in contemporary Havana. His contribution to this volume, 'La Habana: City and Archive', delivers his vision of Havana as a landscape where the politics of memory, urban policies and socialist power produce and re-signify urban ruins. According to him, 'the decayed landscape justifies the discourse of resistance exported by the revolutionary regime, and justifies its rhetoric of a besieged city' (p. 264). There is 'an art of making ruins', which serves the revolutionary power by instantiating a vision of a permanent external threat to the Revolution. Ponte underscores the ethical and political aspects of remembering for the present and the future of Havana. $\mathrm{He}$ integrates post-socialist Eastern Europe into his argument in order to warn Cubans against the danger of amnesia and urban planning as erasure of socialist traces and against 'the danger of seeing the revolutionary period as an empty pause' (p. 265) between two forms of capitalism.

The imagining of the future of Havana among Cuban-American architects as discussed in Nicolás Quintana's contribution is tied to political ideas of liberalism and the ideal of a total sustainable environment. However, this vision is hampered by a shared illusion of a Havana 'frozen in time' or trapped in a 'time capsule' (p. 107). The plans developed in Florida project Havana as a cruise-ship and fishing port in the service of tourism, without any industrial activities. However, what is puzzling in these development plans for a post-Castro Havana is the lack of discussion of the property restitution topic, a highly controversial political question across the two strains of the Florida channel. A cursory survey of this topic in post-socialist Eastern Europe shows that without clarifying the status of property in a post-Castro period, all architecture and development plans will remain pure speculation. Collective forms of community building and renovation projects, as analysed in another chapter by Jill Hamberg, could potentially play an important role in the future reconstruction of the city, especially by preventing gentrification processes. 
Mario Coyula, arguably the most prestigious Cuban architect living in Cuba today, writes about current debates among fellow intellectuals concerning the revolutionary cultural politics, many being critical of the 1970 s highly authoritative cultural politics. He considers that Cuban architecture was harshly affected by technocratic fetishism and repression of individual creativity from the mid-1960s up to the present. His criticism is partly selfcritical (sincere apology, rhetorical strategy or both) since Coyula himself participated in collective assemblies for the expulsion of fellow students and architects accused of ideological deviationism and elitism, as he acknowledges in the text. He depicts Havana as an increasingly dystopian place with a declining civic culture and deplores the spread of popular forms of housing design inspired by Miami architecture or other kitschy Latin American influences. Paradoxically in respect to his criticism of authoritarian approaches, Coyula argues for a harsher state policy (including demolition) to these illegal modifications and unauthorised new constructions.

It is to one of these vernacular types of housing modification that Patricio del Real and Joseph Scarpaci dedicate their chapter, 'Barbacoas: Havana's New Inward Frontier'. These are platforms (made mostly of wood) that subdivide a room into an upper and a lower level and answer the need of finding more habitable space and extra privacy in increasingly overcrowded buildings. The authors argue against the idea of city inhabitants being portrayed as passive victims of the Cuban politics of ruins. Based on their ethnographic, participatory and archival research they claim that barbacoas are not a socialist phenomenon, but go back into the colonial past, and see them as forms of bricolage, defined by informal economy practices and gendered household roles (women's pre-eminent role in household activities, including house re-designing).

Emma Alvarez-Tabio's chapter deals with the muddled sense of time directionality in contemporary Cuba. She takes us back to the 1980s, a Citizen's Decade in her opinion, when various participatory and bottom-up cultural initiatives did create spaces for engagement and reflections about the city's architecture and planning. The 1990 s crisis put an end to these potentialities and opened the city to global influences of capital and tourism, while official urban planning still functions on an anti-market principle.

Sujatha Fernandes explores the ways young black Cubans from marginal neighbourhoods, such as the Soviet-style housing project Alamar, use rap music to express their criticism of growing economic inequalities and racial discriminatory practices on the rise during the Special Period. Nevertheless, the emigration of preeminent musicians, internal political divisions and co-optation from the state are major factors that explain the taming of the resistance potential of the Cuban hiphop movement.

Several chapters explore how Havana is represented and imagined by contemporary Cuban writers such as Ronaldo Menéndez (Laura Redruello’s chapter), Pedro Juan Gutiérrez, Antonio José Puente (Cecelia Lawless), Eliseo Alberto, Leonardo Padura and Senel Paz (Rafael Rojas). Jacqueline Loss's fascinating exploration of recent artistic projects in Havana, which engage critically with state socialism and the Soviet's influence on Cuban society, reveals a city plagued by schizophrenia, delirium and alienation, less confident in a revolutionary bright future. José Quiroga's essayistic contribution is the closest to a Benjaminian exploration of Havana, with dialectical images of music, plastic bags, glasses and sandwiches with guava and cheese.

The reader might be bewildered by such a diversity of themes and approaches, but this is largely due to the palimpsest character of the city itself. It is the merit of the editors to have brought together such a diversity of viewpoints, also by organising the translation from Spanish of most contributions. However, anthropologists and urban sociologists reading this book will miss a more systematic empirical exploration of social practices and materiality in contemporary Havana that would have brought this collection closer to the spirit of Benjamin's Arcades Project. All in all, this book should be considered an exploratory account that will hopefully incite 
more anthropologists to investigate the current transformations of Havana, arguably the Latin American capital of the 20th century.

\section{References}

Benjamin, W. and R. Tiedemann. 1999. The arcades project. Cambridge, MA: Belknap.

Dawdy, Shannon L. 2010. 'Clockpunk anthropology and the ruins of modernity', Current Anthropology 51: 761-93.

MARIAN VIOREL ANASTASOAIE

University College London (United Kingdom)

Bortolotto, Chiara (ed.) 2011. Le patrimoine culturel immatériel: enjeux d'une nouvelle catégorie. Paris: Editions de la Maison des sciences de l'homme. 320 pp. Pb.: €21. ISBN 9782735114177.

Since the pioneering works of historians like Nora, Hobsbawm and Lowenthal in the 1980s, heritage studies has become a large and rich interdisciplinary field. Over the past decade, anthropologists have invested it with particular energy. This French collection of essays not only stands as a manifestation of this surge of interest, but also deals directly with the political event that might have triggered it in the first place: the invention of the notion of 'intangible heritage' and its international consecration as a category of public policy through UNESCO's Convention for the Safeguarding of Intangible Heritage in 2003.

Bortolotto's editorial introduction anchors the collection with a general presentation of the Convention's main features as identified in both her previous work and this volume's essays. These include the controversial 'list' of valuable items, a device modelled on procedures of historic preservation; the Convention's promotion of a type of multiculturalism in which communities of practitioners are both objects and actors of the designation process, yet depend completely on national states' endorsement; and the problematic role of experts in a designation process that is supposed to rest on local knowledge.

The first part of the book focuses on the kind of political structures and relations fostered by the Convention. Maguet provides a Habermasian-Honnethian account of a multicultural public sphere that forms through a triangular relation between national states, markets and communities of practitioners that often do not pre-exist the designation process itself. Using a post-Foucaultian lens, Hafstein looks at these communities as a neoliberal 'governmental' dispositif of subjectivation and subjection. His analysis of the Bolivian origins of the Convention throws a sharp light on a fascinating irony of history: Third World resistance to appropriation of local music by the global (US) music industry merely perpetuated the power of national states and through it global capitalist hegemony. In her analysis of the relationship between heritage and inheritance, Bendix deducts from their semantic equivalence some practical aspects of the mutual dependency between the moral regime governing heritage preservation and the legal-economic regime of modern ownership.

The second section of the volume is resolutely empirical. Four case studies offer precious insights into the Convention's impact on the 'communities' it invokes into being. Noyes' brief but systematic political history of La Patum de Berga festival (Catalonia) provides a remarkably effective illustration of the theoretical analyses provided in Part 1 and more generally of the suitably historicist thesis according to which a heritage event is 'neither an expression of some primitive community, nor the product of some power's invention, nor the manifestation of some people's revolutionary spirit (...) but a formal compromise resulting from a long and difficult negotiation between social forces' (p. 129). Fournier focuses on the substantive aspects of such formal compromise, showing how the designation of a Provençal festival (the Tarasque, in Tarascon) consecrated one of the latest and most innocuous forms it had acquired over the centuries, but also the resolute interpretative flexibility of participants who constantly reinvent the ritual. Macchiarella's 
analysis of Sardinia's canto a tenore foregrounds the contradictions of the UNESCO designation system. Supposed to foster the development of living communities of artistic producers, it remains seemingly unable to assess value without some version of the debilitating criterion of authenticity (embodied here by the list). Bonvoisin and Bartholeyns deliver a somewhat puzzling performance of analysisfiction. Examining whether live-action roleplay could be considered intangible heritage, the essay exposes some limits of the concept, such as (again) its ignorance of the creativity that defines lived practice.

In the book's final section, two essays question the role of experts in the making of intangible heritage. Tornatore discusses the replacement of the scholar-centric model of intangible heritage policy established in France at the end of the 1970s under the name of patrimoine ethnologique by the kind of practitioner-centric model promoted by UNESCO's convention. Somewhat contradicting the French thesis of scholars' destitution (seemingly shared by the editor and by the Ministry of Culture sponsors of this volume), the story of Brazil's Samba de Roda analysed by Sandroni in the last chapter demonstrates that the labour of scholars and experts easily overrides the local community when it comes to create a symbolic inheritance that did not exist and was not perceived as such before.

The book works as an interesting and informative companion volume to what remains the reference collection on the subject (Smith and Akagawa's 2009 Intangible Heritage), with a French twist that is not without special insights. The question of knowledge production insistently raised in the preface, in the introduction and in Tornatore's essay is particularly interesting, for example. One can actually regret that more space and attention is not granted to the role of anthropologists both in the genesis and in the practice of 'intangible heritage' policy. Given the impact of scholarly interests on heritage policy formation since the 19th century, the odds are that this role is somewhat greater than is suggested both by UNESCO ideology, which stresses community empowerment, and by the French anthropologists' perspective, which appears to consider it a primarily 'political' product.

\section{Reference}

Smith, L. and N. Akagawa (eds.) 2008. Intangible heritage. Oxford: Routledge.

\author{
ALEXANDRA KOWALSKI \\ Central European University (Hungary)
}

\section{Chibnik, Michael. 2011. Anthropology, eco- nomics, and choice. Austin: University of Texas Press. 210 pp. Pb.: \$24.95. ISBN 97802927290.}

Michael Chibnik dedicates his book to showing the relation between anthropology and economics in explaining decision-making. As the author claims in the preface, although economic anthropology is less influential than mainstream economics, 'it presents an important, iconoclastic challenge to conventional ways of looking at choice' (p. vii). The whole work is the author's attempt to prove this thesis. To do so, Chibnik builds his discussion around classical issues that economics attempts to solve. The main chapters aim to show how the ethnography-based reasoning of anthropologists differs from the ways in which economists understand and research choice and how both perspectives are valuable in solving those issues.

Chapter one introduces the issues discussed in the book: Chibnik starts with a story of his fieldwork in Belize and depicts that experience as an impulse to consider the importance and limitations of economics, sociology and anthropology in studying decisionmaking processes. The following chapters contain a discussion of five different subjects and outline how the disciplinary paradigms differ in understanding economic phenomena. Chapter two shows the strengths and weaknesses of calculations of the 'utility' of unpaid work. The author uses numerous examples, such as his own research on valuing crops consumed 
at home, and concludes that estimating unremunerated work, although posing a number of limitations, is an important source for studying choices. Chapter three outlines the understandings of decision-making in the conditions of risk and uncertainty. Chibnik stresses how the experiments of cognitive psychologists and models of economists should be accompanied by anthropologists' ethnography-based descriptions. Chapter four is devoted to assessing economic experimental games conducted by anthropologists, whose conclusions, as Chibnik shows using a problem from his own research, have a limited scope of application. Chapter five concentrates on the limitations of using the household as a unit of analysis for understanding decision-making processes. The author concludes that this type of reasoning might be fruitful in certain situations, especially for anthropologists. However, it ought to be under the condition of building 'detailed ethnographic descriptions and analyses of how particular important household-level choices are made in different times and places' (p. 141). Finally chapter six problematises the axiom of the 'tragedy of commons' and some mathematical models of rational-choice following it, pointing out numerous ethnographic examples that provide an alternative view on the issue. His examples reveal rules and institutions embedded in culture that protect communities from tragedies. The conclusion repeats the main arguments of the book and puts forth the necessity for further interaction based on the complementary character of economics and anthropology in studying choice.

The book is essential to any economic anthropologist reflecting on the role of the discipline and its relationship to other social sciences. Chibnik ably answers these questions and provides a complex introduction to how economic anthropologists go about their studies. The author's research experience and his thorough understanding of economic anthropology become evident in the book, which accurately portrays the sins scholars from both sides are tempted to commit. For instance, 'economists too often oversimplify, make unrealistic assumptions, ignore history and culture' and 'anthropologists too often express ideas imprecisely, mindlessly oppose quantification, and refuse to generalize' (p. 171). Chibnik not only reviews the voices of scholars studying the issues in question but also uses examples from his entire work that constitute a valuable source of argumentation. Besides that, his examples provide an interesting perspective on Chibnik's intellectual trajectory over almost 40 years, showing how the field problems found at the earliest stages of his academic career developed into further projects and influenced the conclusions of this book.

The language and outline of Anthropology, Economics, and Choice allows it to serve as a supplementary, yet important, reading for undergraduate courses in economic anthropology. The problems addressed in the volume in an interdisciplinary manner can also be of great value for a broader range of scholars, who will appreciate the insightful discussion about the role of the discipline in solving economic problems and understanding choice. In this sense the book has the potential to become an important contribution to economic anthropology, and interest economists, sociologists and psychologists in an equal manner.

\section{MILOSZ MISZSCZYNSKI \\ Institute of Sociology, Jagiellonian University (Poland)}

\section{Eguavoen, Irit. 2008. The political ecology of household water in Northern Ghana. Vol. 10 ZEF Development Studies. Berlin: Lit Verlag. 328 pp. Pb.: $€ 34.90$. ISBN 978-3-8258- 1613-1.}

In essence, Irit Eguavoen's study is a deromanticised (hi)story of water in the village of Sirigu in Northern Ghana. Her research was conceived and conducted within the frames of an applied project 'Global Change of the Hydrological Cycle' (GLOWA) in the Volta river basin. Its principal aim was to record and analyse mutually related changes of the respective natural environment and the human agency within it. The results could not provide substantial solutions to general development 
issues in this semi-arid African region, but they offer insight into the challenges of freshwater supply in rural and peri-urban environments. The author's epistemic position acknowledges the dynamic interrelationality of natural and social phenomena; thus in her work the local reality - village water shortages - is approached and apprehended holistically. While analysing different aspects of dealing with water from everyday domestic needs and uses of water, to cognitive, normative and legal schemes with regard to water, institutional water resource management, political discourses and popular narratives on water resource degradation, she takes into account both micro/macro and local/global dynamics.

In socio-cultural contexts natural resources transcend their natural dimension, so water could be regarded as a socio-cultural artefact due to the activities involved in household water 'production'. The village under study faces major challenges in this respect, which go beyond environmental and climatic restraints. Water supply facilities (most commonly hand-dug wells and boreholes with hand pumps) are provided by government programmes, big external donor agencies and small NGOs. Financially, Ghanaian rural communities largely depend on external help, i.e. international development interventions, since the donors take on the biggest share (93\%) for project implementation. Although the dominant policy paradigm in Ghana encourages participatory models of water resources management and inclusion of water users in decision-making processes, its application is successful only in urban environments, because the state is basically withdrawing from rural and small town managerial schemes. The financial burden placed on rural communities and the lack of skilled water professionals and clear regulation of management responsibilities are reflected most obviously in the malfunctioning and abandonment of bigger piped water works, as is the case in Sirigu. Consequently, every time the village water infrastructure is left unattended, the consequences are dire.

Speaking in legal terms, water in Ghana is perceived as a (non-exclusive) right for every- one, which is determined by the local water law. The latter is incorporated into (strictly speaking, it coincides with) the statutory water legislation implemented by international (UN) regulations. Various normative levels, as in this case, form a situation of legal pluralism in which different interest groups, competing for limited water resource and protecting their water rights, can call on diverse legal options. In Eguavoen's words, this 'provides a coping strategy to deal with environmental, livelihood, and social and political uncertainty as well as with knowledge uncertainty' (p. 20). The knowledge domain is another sphere of the local/global polarisation. The narratives about the underprivileged economic situation in Northern Ghana (and elsewhere in Africa) are predominantly based on western scientific discourses that appeal to the unfavourable geographic reality of drought, deforestation, overgrazing, soil erosion etc. However, limited natural resources are only part of the story. The legacy of developmental neglect, the application of inappropriate colonial and post-colonial resource management practices (economic overexploitation) and the ignorance of traditional environmental knowledge and local socio-ecologic relationships contribute to the formation of a perspective in which water un/availability can be seen as an outcome of complex geo-hydrological, socio-political and institutional factors. But the ability to grasp this is not the exclusive privilege of scientists. In her detailed ethnographic account of Sirigu's watery landscape, Eguavoen shows that water shortage in local perceptions is not understood as scarcity; people are aware of fundamental financial and technical limitations to access potable water. Their locally oriented collective efforts to create and sustain additional water sources often fall short, but within further development planning their voice and knowledge could and must be acknowledged. What cannot fall short in this case are the efforts of anthropologists to make them heard.

URŠKA STRAŽIŠAR

University of Ljubljana (Slovenia) 
Empson, Rebecca M. 2011. Harnessing fortune. Personhood, memory and place in Mongolia. Oxford and New York: Published for the British Academy by Oxford University Press. 398 pp. Hb: £65.00. ISBN 978-0-19726473-7.

This ambitious and scholarly ethnography explores how the Buriad of Mongolia, a people who traverse the border zone between two countries, and have no private land or state of their own, accumulate possessions, and harness loss and absence, to generate a proliferation of relations. Historically, they have lived under intense persecution during the socialist period, when most of their male relatives were either killed or taken away. Like other post-socialist communities they now confront the rise of a market-oriented culture. Rebecca Empson observes a forceful revival of ancestral and other related ritual activities. A sense of absence from place and kin permeates many aspects of Buriad relations. A recent revival of shamanism has given them access to a particular kind of genealogical knowledge, providing links to and explanations of their fractured heritage. In tandem, a number of iconic and ritual practices have arisen, or been revived, which negotiate the tensions generated by absence and separation from kin and from land.

Empson provides intimate insights into Buriad interiors, physical, spiritual and familial. She identifies within the household chests that all Buriad families use to store treasured possessions, and in the photographic montages that decorate and dominate their domestic spaces, assemblages that bring relations into being through singular or juxtaposed things that are deliberately displayed or concealed from view. These situate among a continuum of practices by which people are separated from certain connections in order to establish a more singular mode of subjectivity. By illuminating this need to sever connections and enact discontinuities between persons, Empson alludes to Strathern's idea (1996) that curtailment and limit is also a form of relationship.

The 'fortune' that supplies her title is central to Empson's investigation. It is difficult to determine its presence or quantity, but a portion of it can be harnessed, and its fecundity may be brought into households. She compares this concept to the Polynesian concept of 'mana', and to the Japanese practice of 'beckoning luck'. Since 'fortune' resides within herds and other collectivities, isolating it in order to preserve or 'harness' it requires of the Buriad an encompassing approach to relations with kin, with possessions, with their animals and, particularly, with the land across which they and their herds migrate. Empson highlights ceremonies conducted at the cairns, or ovoos, that are a ubiquitous feature of the Mongolian landscape. She observes that these practices reflect the notion that humans do not hold land as they do other mundane possessions, but enter into relations with the spiritual powers of the locality to ensure favourable conditions. Making offerings at the ovoo is a means by which different interest groups, including far-from-traditional ones such as gold miners arriving in blacked-out jeeps, can visibly enact their good relations with such spiritual stewards of the land, and claim some form of custody over it. As they root themselves to the landscape by placating its past inhabitants, the Buriad gain knowledge of the past that becomes a kind of tool for the present.

Reflecting upon the widespread belief in intra-kin rebirth, Empson argues that the absence of certain people, and the lack of conclusive reason for their disappearance, which is such a powerful phenomenon in recent Buriad experience, persists in people's memories through intra-kin rebirths as a 'remainder'. This generates the possibility for the imagining of new subjects. With no official way to commemorate their loss, rebirths are one way in which people can tend to the disappeared and silently incorporate them back into families.

Harnessing Fortune contains much further richness of ethnographic detail, ranging from the particular role played by mirrors in the Buriad construction of selfhood, to the frequent occurrence of arson attacks on houses, which Empson compares with witchcraft accusations in other, particularly 
post-colonial, communities where there are tensions consequent upon rupture with the past, and where some seem to accumulate wealth and fortune effortlessly, while others seem to have none of it at all. The book's arguments are informed by such recent theorists as Alfred Gell, Bruno Latour and Eduardo Vivieros de Castro. Yet though scholarly, Harnessing Fortune wears its learning lightly. Above all, Empson's writing is suffused with a deeply personal connection to a people who, as she asserts, are not living in a way that they consider to be 'transitional'. It is her conviction that the Buriads' daily experience testifies to the power of Caroline Humphrey's assertion that 'the unmaking of earlier ways of living and the putting together of new ones are always mutually constitutive' (2002: xxiv).

\section{References}

Humphrey, C. 2002. The unmaking of Soviet life: everyday economies after socialism. Ithaca: Cornell University Press.

Strathern, M. 1996. 'Cutting the network', The Journal of the Royal Anthropological Institute incorporating Man 2: 517-35.

DOMINIC MARTIN

University of Cambridge (UK)

Feyissa, Dereje. 2011. Playing different games. The paradox of Anywaa and Nuer identification strategies in the Gambella region, Ethiopia. New York and Oxford: Berghahn Books. 254 pp. Hb.: $\$ 95.00 / £ 56.00$. ISBN 978-0-85745-088-3.

In 1995 a new constitution was adopted in Ethiopia, introducing federal states based on ethnic principles. While most states are the home country of only one people with a common language and culture, other states are multi-ethnic, such as Gambella. Here the two most important officially recognised groups are Anywaa (or Anuak) and Nuer, both of which are also at home in the adjoining areas of Sudan, with which Gambella shares a similar natural environment. The relation between Anywaa and Nuer in Gambella is fraught with tension that erupts in violent clashes, as in 1998 when in Itang, an area with a mixed population, a family quarrel escalated and 60 people were killed, ten villages burned and 3000 persons displaced before a state of emergency was declared after several months to end overt hostilities. This came as a real shock for the author, an Ethiopian anthropologist who was working for an NGO in the state capital at the time.

In the present study, based partly on later research for a $\mathrm{PhD}$ degree, Feyissa provides us with an extended historical background for this incident that was preceded and followed by several similar confrontations. He expertly analyses their intricate ramifications and interconnected causes (although I sometimes felt that his presentation could have benefited from more and better maps). Many dimensions of the problem are shown to be relevant. At the international and national level they include the way Gambella and its inhabitants were drawn into the almost continual civil warfare in South Sudan since 1955, and the exploitation and manipulation of this conflict by successive Ethiopian governments that pursued their own interests rather than having the peace and prosperity of its Gambella citizens at heart. At the regional level Feyissa considers among other things the role of elites who compete for salaried jobs through control over appointments and, indirectly, over access to education.

For ordinary villagers, the availability of farmland and pastures is of crucial importance. Although in the early part of the 20th century Nuer use of pastures did not compete with Anywaa cultivation of crops, Nuer cattle wealth and willingness to intermarry resulted in a faster population growth of Nuer communities. The demographic balance and spatial distribution was altered even more when after 1983, as a result of the spread of modern firearms, groups of Sudanese Nuer 
were able to occupy Gambella areas for their sole use and also caused well-established migrants belonging to other Nuer sections to seek refuge elsewhere. In the 1980 s resettlement of Ethiopians from the Highlands in Gambella after widespread and severe famine and the imports of cheap food for refugee camps also had an adverse impact on Anywaa farming.

Although I have dealt here only with some of the aspects covered by Feyissa, it should be clear that there was plenty of scope for attributing negative stereotypes by Anywaa to Nuer and the other way around, blaming direct competitors rather than what had caused competition in the first place. Feyissa sees the origin of how Nuer and Anywa perceive each other in the way they experience their own identity, which corresponds to two different theories of ethnicity: the Nuer are 'constructivists' and the Anywaa are 'primordialists'. As polar opposites, these identification strategies allow Nuer to condemn Anywa for resisting assimilation and Anywaa to accuse Nuer of conspiring to annihilate them in the long run. Granted that these terms may be useful metaphors to call them incommensurable language games suggests that any form of communication between Anywaa and Nuer would be difficult, if not impossible, and would deny the possibility of reconciliation and peaceful coexistence under different circumstances. However, language use depends not only on semantic-referential meaning but also on indexical meaning (pragmatics). That opens up the possibility that people might be able to discount political rhetoric (and most examples given by Feyissa are just that) in contexts of interaction where they believe that different values should prevail. From older ethnographies we learn that at least in the past Nuer feuding was contained in that way and that Anywaa were experts in distinguishing between what people say and what they actually do.

Very sadly the situation of both Nuer and Anywaa has changed for the worse since 2005, which period is not covered in this book, as large tracts of fertile land have been leased to foreign investors, apparently without any consideration of the present and future welfare of the local inhabitants.

\section{JAN DE WOLF \\ Utrecht University (The Netherlands)}

Fox, Katy. 2011. Peasants into European farmers? EU integration in the Carpathian Mountains of Romania. Berlin: Lit Verlag. 360 pp. Pb.: €34.90. ISBN 978-3-643801074.

The volume under review offers an intriguing combination of a 'classic' approach to postsocialism focused on processes of change such as decollectivisation, pluralisation and marketisation, and an exploration of new subjectivities, of issues of resistance, personhood and hope. The monograph draws on longterm fieldwork in two Romanian villages on the south versant of the Carpathian Mountains and in the capital, Bucharest, in various agencies subordinated to the Ministry of Agriculture.

As the title suggests, at the core of the argument lies the divide between peasants and farmers created by modernist schemes involved in EU agricultural policies. The author shows how this ideological divide, and the broader neoliberal agenda to which it belongs, impact real lives by creating hierarchies, categories and devaluation. At the same time she shows how possibilities, hopes and resistance are interwoven in agricultural livelihoods in the Romanian Carpathians. At the theoretical level, the author's questions exceed the particular eastern European context appealing to anthropologists working in other areas of the world affected by neoliberal projects and enlightenment epistemologies of rational choice and 'modern ways'. Some of the questions she raises reflect on 'the differences between political projects and life projects' (p. 32); the extent to which political projects exert control over people and their resistance to it (p. 37); and the ways in which people make sense of their lives and cope with political projects. 
Several chapters provide a fine-grained analysis of food and alcohol production and meat processing and sale, examining in detail pig sticking practices, the restructuration of markets and the meat sector, and the home distillation of plum brandy. The author shows how restructuring local and national markets led in practice to the acceleration of commercialisation and the creation of large agribusiness, resulting in branded and certified products, and, at the other end to the exclusion of small-scale producers. In light of these processes, traditional peasant' identities, strongly interconnected with household-based animal husbandry, started to look belittled, and in response, peasants started questioning neoliberal logics of the market. In this economic game, small producers became losers and were being labelled 'made in socialism', as opposed to 'winner' producers that adopted more entrepreneurial strategies, going with the capitalist flow.

Another tool for creating devaluation and hierarchies within villages was the EU policy of direct payments, described by the author in the chapter 'Implementing: Direct payments, land and confusion'. The entire procedure of implementing the policy created a cartographic illusion (moving from land as territory, which is a 'sensuous reality', to land as a map) and suggested an absolutely agentive model of personhood, conceiving the person as selfmade, 'separate from her human companions and her environments, and free' (p. 176).

The book draws a rather pessimistic picture about systematic devaluation and exclusion. The Common Agricultural Policy, based on normative notions of integration, information, training and welfare, proved to be unsuccessful in producing the intended effects, and triggered feelings of failure, hierarchies and polarisation. Integration did not offer all rural inhabitants the possibility to participate, since information about agricultural programmes, supposed to be diffused through institutions, did not reach out to peasants who were then blamed for their 'unawareness'.

As the peasants did not fit into the neoliberal logic, they started to feel inadequate, powerless and immature, in need to be 'colonised' (p. 295) by expert know-how. In this context, Fox tries to capture the 'collective drift of change' (p. 237) and shows how ordinary people were driven by and resorted to three kinds of intertwined 'manoeuvres' (a concept she borrows from Gramsci), in order to continue making a living. She depicts 'manoeuvres of limitation', which make peasants perceive their freedom of movement limited by EU-driven policymakers that seek to codify reality in rigid frames (e.g. the regulation of transhumant movements and the ban of sale of peasant produce on the market); 'manoeuvres of separation', in which people morally contrast a radiant past and future to an unclear present, controlled by immoral mafia-like forces, promoters of inequality and trickery, from which the peasants disconnect; and 'manoeuvres of obfuscation', as strategies of vagueness and secrecy that kept decisionmaking open and illegal practices going.

The high intensity of the book, understood both as concentration of information and passion with which the author tries to make in-depth sense of complex realities, are at the same time its virtues and pitfalls. A large cluster of characters, events, trajectories and narrative snapshots, fitted into several theoretical frameworks might at times feel like an overflow of information and suffocate the reader. Nevertheless, the monograph treats in a powerful and novel manner various themes, while offering extensive ethnographic knowledge of the people involved, their manifold ideas, motivations and aspirations.

\section{MONICA VASILE \\ Max-Planck Institute for Social Anthropology \\ (Germany)}

Ghodsee, Kristen. 2011. Lost in transition. Ethnographies of everyday life after communism. Durham and London: Duke University Press. 232 pp. Pb.: \$22.95. ISBN 978-08223-5102-3.

This publication is likely to evoke mixed feelings. On the one hand, it succeeds in bringing 
to life the changes that affected ordinary people in Bulgaria from the breakdown of the Berlin Wall in 1989 till present. On the other hand, it leaves a lot unanswered. At the expense of theory, the author explicitly commits to a thick ethnography of people's experiences of the transformation from state socialism to the EU-framed political democracy and market economy. Some of these stories are documents of individual lives; others are cases of ethnographic fiction, things that ring true although they might not have happened exactly as described. Perhaps written for a Western audience influenced by the Cold War representations of communism as a grim, repressive reality, Ghodsee explores 'postsocialist' ambivalence, nostalgia, the sense of loss and anger of Bulgarian individuals. By gradually adding layers of complexity to the book, Ghodsee presents us with an adroit portrayal of her personal journey from a biased but inquiring teenager fearful of the imminent nuclear annihilation to a mature scholar aware of the dangers of prioritising the analysis of the political and economic systems in Eastern Europe over people's quotidian existence. It would have been impossible to understand from the former, structural point of view what people miss most about socialism and how, in the sea of change, they aim to preserve little things like a polite form of address, a flavour of coffee, or lost opportunities to realise one's dream of winning a socialist competition, made irrelevant in the 1990s.

The author taps into a rich repertoire of suspicions and conspiracy theories about communist and democratic elites, corruption and lack of transparency under different political governments in Bulgaria. This way Ghodsee avoids the black-and-white descriptions of Bulgarian socialism and of what came next. She juxtaposes, for example, the narrative of a woman who was separated from her lover by the communist secret services with a story of a young Muslim woman who is nudged toward prostitution by postsocialist economic desperation, unemployment and insecurity. An accurate description of consumer shortages and smuggling of Western goods like Heinz ketchup is implicitly related to the new entrepreneurial adventures (basically scams to swap antique Bulgarian rugs for Chinese plastic carpets) that take advantage of people's poverty and ignorance of the true value of their possessions. Poignantly, Ghodsee explores how young people are torn between economic benefits of working in the West, longing for a decent life at home, and disappointment with the quality of life and human relations in Bulgaria. The whole book is an endless seesaw between initial optimism and subsequent 'disenchantment with the coming of democracy' (p. 177).

I have found the book refreshing and easy to read. This is not a masterpiece of ethnographic prose, but I would gladly recommend it to undergraduate students who, as Ghodsee points out, struggle to understand why anybody would look warmly at a totalitarian regime (p. 178). Ghodsee's explanation is that relative economic security, appealing ideological idioms of social justice and the rhythms of daily lives compensated for the overarching presence of the restrictive oneparty regime. Where I disagree slightly with Ghodsee is in her brief analysis of the roots of disenchantment with the present system. For her 'it is the process of transition and the poor way it was handled in many countries that lies at the root of the growing nostalgia' (p. 183). However, the crucial question that the book does not answer is what kind of transition Bulgarian people experience today. The ethnographic episodes of the late 1990s would suggest that this is how people felt at the time, but what about their nostalgia for communism today? In a superficial sense, Bulgarians have reached their destination: the country has joined the European Union (although on unequal terms with other EU countries). In this sense their formal transition is over. Yet practically, no democracy, political institution or economic experiment is stable; the EU itself is caught in an on-going, difficult 'transition' of a kind, and Bulgaria is part of this process too. It is not clear why the uncertainty that Ghodsee's interlocutors face today is framed in the language of the postsocialist transition when frustration with one's actual, ordinary realities might be an intrinsic quality 
of socialism, democracy, capitalism and market economy rather than of the poor handling of transition as the author claims (pp. 184, 186). A more comparative agenda that would relate the Bulgarian case to an overwhelming sense of disappointment with democracy-inspired projects across 20th and 21st century Europe (Mazower 1998) is likely to better answer this question.

\section{Reference}

Mazower, M. 1998. Dark continent. Europe's twentieth century. London: Penguin Books.

GALINA OUSTINOVA-STJEPANOVIC

University of Edinburgh (Scotland)

\section{Jeffery, Laura. 2011. Chagos Islanders in Mauritius and the UK. Forced displacement and onward migration. Manchester: Manch- ester University Press. 224 pp. Hb.: $£ 65$. ISBN 9780719084300.}

The global system's inherent contradictions regularly generate constellations that provide entry points for anthropological research about those critical junctions that allow for dense and thick descriptions of historical processes of exploitation, annihilation and their ideological foundations. One such constellation emerged in the Western Indian Ocean when the inhabitants of the Chagos Archipelago were deported in the years between 1965 and 1973 to make way for one of the largest US military bases in the world. Three years prior to the independence of the British colony Mauritius, this archipelago was transferred into a new administrative unit, the British Indian Ocean Territory (BIOT). As part of what has been identified by Vine (2009) as the 'Strategic Islands Concept' of the US Cold War machine, the British government leased the central island of Diego Garcia to the US government and rewarded the postcolonial Mauritian government with a then substantial compensation for its silence over the issue. At the same time, the inhabitants of the former copra plantation settlement were deported to Mauritius and the Seychelles and left there to make a new living. Neither Mauritius nor the Seychelles were particularly prosperous places in those days and it took the deportees several decades before their protests against deportation, ensuing poverty and discrimination in the receiving countries caught the attention of a larger, global audience. Once these people, by now declaring themselves 'Chagossians', launched a series of high-profile court cases against the British and the US government in UK courts in the late 1990s, they also caught the attention of numerous anthropologists.

Laura Jeffery's book under consideration here is the second monograph to emerge from such research. The book itself is highly accessible and manages well to break down the complex entanglements of the Chagossians' struggle within Mauritius and with the UK legal system. Those struggles resulted in some Chagossians migrating to the UK after receiving British passports, but did not grant others the right to resettle on the Chagos islands. While significant parts of the six main chapters are based on previously published works, the book presents a significantly extended and clearly written narrative. The introduction outlines the author's main concern with analysing the Chagossian story along categories such as displacement and forced migration. Chapters 1 and 2 give a historical background on colonial settlement of the Western Indian Ocean and how the changing global constellation in the post-1945 era not only resulted in the Chagossians' deportation but also meant that their life and times in Mauritius were shaped by the local manifestations of Cold War politics. Chapters 3 and 4 then scrutinise how Chagossian narratives of homeland and exile became stronger over the decades and how the limited quality of life prior to 1965 was increasingly portrayed as paradise in exile. This is then coupled with a discussion of the politics of culture in exile, focusing on the preservation of traditional dance, music and cooking, for example. Chapters 5 and 6 turn to the fate of those Chagossians who have migrated to the UK and mostly ended up 
living near and working at their place of entry to the UK, Gatwick Airport. Here the focus is no longer on the preservation of traditions but on outlining how onward migration has changed the migrants' views of Mauritius and how this can be compared to their earlier and different displacement from Chagos to Mauritius.

There are several points that will surely trigger some discussion of Jeffery's book. For one, the potential that the story of the Chagossians offers lies fallow because the volume is thin with regard to extent and substance. Manchester University Press claims 224 pages for the book, but there are actually only 155 pages for references, endnotes, blank pages between chapters and an index plus 20 further pages with Latin pagination that contain no ethnography. This comes at a price. Although it is often evident that Jeffery has generated an impressive body of data over several years of research, both ethnohistorical and ethnographic foundations for most conclusions drawn seem rather flimsy. This ranges from claims that life in Chagos is romanticised in exile while there was actually a sexist and racist plantation extending into the interactions of the islanders that are based on rather thin materials taken from the lyrics of songs for example (pp. 62-7), to contradictory evidence on the actual position of the Chagossians that shifts from tracing their marginal position in Mauritius up to the present in Chapter 1 to showing how central their story is for Mauritian domestic and foreign affairs in Chapter 2. Furthermore, Jeffery takes little notice of the existing body of literature on the Chagossian case, ranging from several graduate theses surely available to her (e.g. Johannessen 2005) to an excellent monograph (Vine 2009), which address very similar examples but provide a more sophisticated theoretical reflection on the subject.

\section{References}

Johannessen, S. 2005. 'Contested roots. The contemporary exile of the Chagossian community', MA thesis. Department of Social Anthropology, University of Oslo.
Vine, D. 2009. Island of shame. The secret history of the U.S. military base on Diego Garcia. Princeton, NJ: Princeton University Press.

PATRICK NEVELING

University of Bern (Switzerland)

Kousis, Maria, Tom Selwyn and David Clark (eds.) 2011. Contested Mediterranean spaces. Ethnographic essays in honour of Charles Tilly. New York and Oxford: Berghahn Books. 330 pp. Pb.: \$120.00/ £75.00. ISBN 9780857451323.

Dealing with the Mediterranean as a meaningful framework for social and cultural analysis is not an easy task. Beyond the self-evident truth of a cultural geography moulded by a long history of interrelations and connections as well as conflicts and separations, essentialist ideas of 'Mediterranean-ness' loom over the same historical complexities of the region. However, over the last 10 years several attempts were made to overcome the shortcomings of an oversimplifying approach to the Mediterranean region. Although these attempts are not always related to each other, they seem to express a common attitude toward the need of problematising the cultural geography of an area which far from being homogeneous, has been and is involved in a set of political, economical and social processes marked by cleavages and conflicts. That is the case of this edited volume, which provides a wide range of ethnographies concerned with 'contested spaces' - from museums to urban planning, from environmentalism to the appropriation of religious sites and to musical festival skilfully framed within a common set of problems, perspectives and structural processes. Its aim as acknowledged in the introduction is to 'locate the collection of essays within a framework of overlapping spaces' and to 'express the dynamics of social structure and processes within these spaces in terms of relationships between politics, capital and identity' (p. 1). 
The editors acknowledge the influence of Charles Tilly, which orients the general perspective of the book towards the controversial construction, appropriation and definition of 'space' in (mainly) urban contexts. Tilly's influence is likewise noticeable in the emphasis on cities as fruitful viewpoints to explore the connections between local, national and supranational layers (p. 3). Most contributions suggest that the analysis of social and political processes in Mediterranean cities would provide a steppingstone to the understanding of the ways global economic and political processes intervene in the production of space in small-scale sites.

The thirteen chapters that make up the book are divided into four parts. Part 1, 'Recovering the Mediterranean', contains three essays on the problematical issues related to the thickness of meanings that overlap into the rhetoric of 'Mediterranean-ness', with reference to the region's relationship with the European Union. The opening chapter (Vassiliki Yakoumaki) provides a critical assessment of the EU-funded Med-Voices project - 'Mediterranean Voices: Oral History and Cultural Practices in Mediterranean Cities' - in which several contributors to this volume took part. Reflecting on the mutual influence between scholars and institutions, Yakoumaki addresses the problems of doing research within a framework established by EU cultural politics, and the 'bureaucratic essentialisms' ( $p$. 18) researchers faced in the production of positive representations of the Mediterranean. The following two chapters devoted to European 'securitisation' policies on the Southern fringe (Minas Samatas) and a music festival gathering the different Mediterranean musical traditions (Eleni Kallimopoulou), focus on the controversial attitudes of the EU towards the Mediterranean, marked by political and military practices of exclusion and contradictory attempts of rhetorical inclusion on the ground of common 'traditions' and cultural features.

The essays in Part 2, 'State, Capital and Resistance', bring us to another level of cleavages, partly related to the larger political processes outlined in Part 1, the new Euro-Mediterranean policy. These processes are articulated on different scales and conceptual layers: the city, State and civil society relationships, environmentalism, science and community based activism. On a smaller scale of analysis, that of the neighbourhood, Part 3, 'Capital, Neighborhood Governance', explores the relationships between local patterns of social action and political and institutional frameworks and the ways these are influenced by the flows of global capital. Particularly challenging issues are raised by a detailed ethnography of the gentrification process in the inner city of Palma de Mallorca (Spain), in which the overlapping of networks and discourses on the city brings about controversial parallel processes of urban re-qualification and social exclusion (Marc Morell and Jaume Franquesa). The neighbourhood then reveals itself as both an effect of top-down policies and a site of conflict and exploitation - a contentious and contested space. Finally, Part 4, 'Transforming Identities: Imagination and Representations', focuses more directly on several case studies concerned with the production of cultural difference and the conflictual appropriation of spaces: Jewish museums in Italy (David Clark), a multi-religious neighbourhood in Granada (Javier Roson Lorente and Gunther Dietz), a religious site in Palestine (Tom Selwyn) and a festival in Greece (Elia Vardaki). In all of these cases the overlapping of different local practices intermeshes with the complexities of geopolitical situations and socioeconomic processes on a larger scale (such as migration flows, the Israeli-Palestinian conflict etc.).

One may notice that certain unifying features of the volume - a critical approach to EU cultural policy, its focus on global capital flows, an attention to the conflictual dimension of social processes etc.) are anything but new. None the less by insisting on contentiousness and the unstable characters of identities and politics that are continuously reproduced within and across the region, the collection testifies to an innovative attitude, providing an insightful framework for the understanding of the Mediterranean as a complicated whole. In doing so the volume breaks away from the fixed circularity of stereotyped representations of the Mediterranean, relocating it within the 
complexities and interconnectedness of global processes.

\section{ANTONIO MARIA PUSCEDDU}

University of Cagliari (Italy)

\section{Krause-Jensen, Jakob. 2010. Flexible firm: the design of culture at Bang \& Olufsen. New York: Berghahn Books. 318 pp. Hb.: \$85.00. ISBN 978-1-84545-668-9.}

Purity, simplicity and exclusivity constitute the design characteristics most often associated with Bang \& Olufsen (B\&O) - 'one of the crown jewels of the Danish manufacturing industry', as Krause-Jensen puts it. Quite literally in fact: the company is Purveyor to the Royal Danish Court and a favourite of her Majesty Queen Margrethe II, when foreign dignitaries are bestowed with gifts. One would think that such a powerful and iconic corporation would not need any branding. Not so! In 1999, when Krause-Jensen embarked on his fieldwork at $\mathrm{B} \& \mathrm{O}$, the $\mathrm{CEO}$ decided to double the marketing budget to 100 mill DKR (€15mill). From the vantage point of the Human Resource Department (HRD), the anthropologist explores the translation of this allocation into managerial visions of 'corporate culture' and how this discourse is distributed, received, experienced and reacted to by the employees at various floors of the corporation.

The book falls in three parts: Section I sets out the methodology and theory; section II mines the corporate history and section III details the ethnography. The first two chapters deal with the challenges of conducting fieldwork among 'radically reflexive and theorized' (p. 39) employees, who produce conceptual descriptions drawing on academic culturalist discourse. This implies that the analytical map of the anthropologist and the empirical terrain of his interlocutors at times conflate, which leads to what Krause-Jensen dubs 'fieldwork among lay ethnographers'. Commuting between his home in Silkeborg, his alma mater in Aarhus and his field site in Struer, we are literally in the backyard of the anthropologist.
The virtues of the home turf are the painstaking detail, precision, saturation, solidness and plasticity of the ethnography; the vices seem that Krause-Jensen is never really pulled out of his homey comfort-zone, which makes his credo 'strangeness does not start on the other side of the ocean, but at the tip of the nose' (p. 168) less convincing.

The third chapter deals with the key question of how to conceptualise the relationship between power and culture, or in this case between the discursive registers of management ideology and the agency of employees within a single organisation. The contours of two competing conceptualisations of power are delineated: Weber's notion of the 'iron cage' of rationalisation and Foucault's notion of the 'panopticon'. Krause-Jensen resolves the competition by accommodating both theorists, arguing that $\mathrm{B} \& \mathrm{O}$ is in fact a 'glass cage', which enables effective surveillance that produces certain forms of subjectivity and selfmanagement through a corporate discourse of transparency and accountability. Within this framework he elucidates the paradox of being a successful employee and at the same time realising one's subjectivity in a deeper existential sense. By and large, Krause-Jensen's advances a Focaultian governmentality perspective supplemented with a dash of Barthian agency.

The second section takes us through the shifting corporate discourses from 1925 to the late 1990 s in four chronological chapters. This corporate history boils down to a couple of discursive shifts in managerial discourse, the most significant being from 'product-driven' over 'culture projects' to 'value-driven'. Staying true to his theoretical marriage of Foucault and Barth, it is not all discursive fields. However, Krause-Jensen misses analytical opportunities for a more sustained engagement with these discursive shifts, beyond the employee interpretation of 'if anything is constant, it is change' (p. 78) and Sahlins' structuralist mantra of 'plus ça change plus c'est la même chose' (p. 145). These shifts could have been productively linked to the new knowledge production at leading business schools, transnational market trends, the organisational visions of the 
'cultural other' (SONY), or corporate values of those closer to Scandinavian modernism such as LEGO or IKEA.

The corporate history serves primarily as the pre-history of Krause-Jensen's fieldwork and sets the stage for his ethnography on the reception of the 'fundamental values' of 'excellence, poetry and synthesis' among the employees. In the course of 6 months in 1999, he heads to the canteen during lunch breaks, conducts interviews in Product Development (PD), attends meetings and observes and participates in the workings of the HRD. His ethnography picks up broad scepticism towards the 'three dirty words' conceived to strengthen the ethos and common purpose of the organisation. $\mathrm{He}$ finds that 'the abstract nature of the values' (p. 187) polarised and split the management from the staff, as well as the HRD from the PD. The ethnography in section III reveals two paradoxical relationships between flexibility vis-à-vis experience and formalisation. Firstly, contrary to the widely held assumption that younger employees thrive in informal network-organisational structures and seniors fail, it was the experienced engineers, without exception, who preferred the new flexible organisation to the older departmental divisions (p. 262). Secondly, flexibility did not reduce formalism, bureaucracy and regulations; rather 'a certain kind of bureaucracy seemed to be an unavoidable consequence of the flexible strategy itself' (p. 271).

The book stands out and is likely to become a touchstone monograph in the emerging field of the Anthropology of Business \& Organization. However, the work is severely hampered by what Van Maanen in the Foreword defines as 'a kind of theoretical cocktail to which the author himself testifies: "I am shamelessly eclectic"' (p. 20). We are invited to make sense of an organisational micro-cosmos through an analytical tour-de-force with shifting theoretical guides for each chapter and too many nods to disparate bodies of theory at each page. The analytical repertoire is sweeping and the readings of the different theories are well articulated, but it all adds up to a series of lesser attempts to unpack and elucidate the conceptual triangulation of culture-poweragency - less would indeed have been more. However, this theoretical kaleidoscope represents the author's genuine attempt to come to terms with and understand his material over a decade of writing. The problem is that it reads as a piecemeal puzzle, rather than a crafted and compelling argument, where the theoretical purchase of different concepts is juxtaposed, challenged and really put at stake.

That being said, the book has a powerful and enticing storyline: the struggle for the 'true soul' of $\mathrm{B} \& \mathrm{O}$, between the 'sincerity' of the $\mathrm{PD}$ and the 'artificiality' of the HRD, between minimalist Scandinavian modernism embedded in Jutlandian modesty and the aggressive and high-flying rhetoric of brand gurus from metropolises. This tale is well told, pitched as an 'I-witnessing/they-picturing' story of being there. But there are limitations to such an account, which stays so close to the actions and metaphors on the ground in North-west Jutland. Larger questions beyond the microcosmos of $\mathrm{B} \& \mathrm{O}$ are left out: To what extent does the flexible organisational culture of $\mathrm{B} \& \mathrm{O}$ reflect the official Danish labour market model 'flex-security'? To what extent does globalised market capitalism shape the 'corporate culture' of $\mathrm{B} \& \mathrm{O}$, rather than the host of local CEOs and brand gurus we meet? Such questions are pertinent, but not posed, simply because they seem out of reach for the type of ethnography Krause-Jensen seems committed to.

\section{MARTIN SKRYDSTRUP \\ University of Nairobi (Kenya)}

\section{Lambek, Michael. 2010. Ordinary ethics: anthropology, language, and action. New York: Fordham University Press. 400 pp. Pb. \$30.00. ISBN 9780823233175.}

This edited volume constitutes a remarkably strong incentive to abandon power and structures in favour of ethics for explaining social reality: ethics as a dimension of all human actions, 'a property of speech and action, as mind is a property of body' (p. 61). The book is 
a demonstration, chapter by chapter, that ethics is part of the human condition, present in every social and human experience, from ordinary talk to cosmologies. The volume includes 20 contributions, mostly from anthropologists, and covers a geographically wide range of case studies that lead us from Asia to Australia or Amazonia, passing through London or the Abu Ghraib prison.

The location of ethics between the spoken and the unspoken, between objectification and embodiment, its attention to reveal the tacit and the implicit as well as its sensibility to the difference between 'is' and 'ought', are the strength of 'ordinary ethics' - as, in addition to the fulfilled promise that is the book, ordinary ethics positions itself as a research programme for the future: 'We locate the ethical in the conjunction or movement between explicit local pronouncements and implicit local practices' (p. 7). The book shows that the anthropology of moralities - or ethics - could not be reduced to an ethno-ethics, a comparative ethnography of explicitly asserted moral frames. Although not all chapters depart definitely from this ethnological approach, their putting together and the variety of aspects covered helps make the important point that ethical sensibilities should be looked for beneath every action. And, if this claim was also that of Durkheim (with the entailing risk that the ethical dilutes into the social), here the implication drawn is different: if every social fact could be morally charged (sometimes neuter), this does not derive directly from the equation society $=$ moral commitment, but should be analysed and proved in all its complex intertwinement between 'ought' and 'is' present in every aspect of human life. One cannot but note that this position is different from recent research on moralities that place themselves as anti-Durkheimian by stressing the singularity of moral reasoning and constituting it as a subject on its own that would correspond to a distinguishable part of the social realm.

Without being programmatic, normative or embracing the new forms of global militantism, the editor Michael Lambek highlights the contemporary relevance of ethical ques- tions: 'one of the questions implicitly raised is whether and how ordinary ethical sensibilities are coarsened or heightened with respect to broad social forces such as consumer capitalism, media advertising, inequality, violence, and specific forms of discipline, such as bootcamp army training' (p. 3). Furthermore the volume tries to avoid the relativist/universalist debates involved in cross-cultural moral judgements (notably in human rights debates). The editor asserts that taking ethics to be a property rather than an object (an Aristotelian instead of a Kantian definition) should prevent the contributors from explaining ethics in rationalist, utilitarianist, biological or other deterministic terms. Getting away from normative judgements, not being reductionist in explanations and circumventing the relativist/universalist debate is a very stimulating agenda that one could not but support. Though some questions arise. Firstly, whether the wish to remain innocent of the normative implications of an ethnographic analysis could be sustained and, secondly, if evacuating rationalist terms of explanation will not totally blind us to scientific facts. I will illustrate these questions with just one example from the book.

The focus on ordinary action versus extraordinary, deviant phenomenon alleviates the problem of the neutrality of the observer by reducing the weight of the issues at stake. But could this position be maintained when studying prison abuses conducted by American soldiers in Iraq (the chapter by Steven Caton)? Here Caton positions himself in favour of a study in terms of situational evil rather than in terms of transcendental values; his arguments are subtle and convincing and well maintain his neutrality. But what would have happened if his description were intended to inform the normative, facing the pragmatic need to evaluate, judge, make a decision? In his critique of Amartya Sen's The Idea of Justice (2009), the philosopher Wilfried Hinsch (2011) argues that without an (transcendental) idea of the good, there is no way to judge what is better or worse and advance towards the good. When the ethical is just a property of things, based and transmitted through the experience 
of the past, how do we know what is more ethical, in the absence of a socially (sometimes globally) constructed idea of ethical thinking? And, finally, shall we abandon rationalist, biological etc. criteria as being too reductionist instead of maintaining them as the backbone of judgement, to which experience, emotions, contingencies should be added in order to describe human complexity?

Linguistic anthropology inspires many contributors to the volume and refines their interactionist and dynamic approach. The ethical action (including the act of speech) is made through human interactions and is analysed through their observation, with a careful attention given to details, nuances, micro-changes, levels of meta-thinking. Divided in seven parts, the volume tackles agency, responsibility, etiquette and aesthetics, punishment and dignity, in ordinary and extraordinary actions. It brings with it a refinement of terms and exemplary analyses of contextual situations that should remain inspiring for general social anthropology.

\section{References}

Hinsch, W. 2011. 'Ideal justice and rational dissent', Analyse E Kritik 02/2011: 371-86.

Sen, A. 2009. The idea of justice. Cambridge, MA: Harvard University Press.

MONICA HEINTZ

Université Paris $X$, Nanterre (France)

Lindhardt, Martin (ed.) 2011. Practicing the faith. The ritual life of PentecostalCharismatic Christians. New York and Oxford: Berghahn. 336 pp. Hb: \$95.00/ f55.00. ISBN 978-1-84545-770-9.

This fine volume addresses the apparent oxymoron of Pentecostal-Charismatic ritual what Joel Robbins refers to in his contribution as one of its 'obvious aspects': not essences, meanings or contents of beliefs or doctrines, but the outward, observable things people are actually doing as participants in religious activity (and what it does to them). This perspective on the various permutations of charismatic Christianity has been taken by only a few studies, which serve as the main body of literature to which nearly all the essays assembled here refer (most notably, the work of Thomas Csordas, Tanya Luhrmann and Simon Coleman). Martin Lindhardt suggests in his introduction that ritual practices can provide a new lens through which to look at most of the central issues that research on global Christianity focuses on: how Charismatics construct the social reality of God's presence, as well as the Devil's; how they build a community; what is behind their use of popular culture and mass media; how and why their spiritualisation of the quotidian is realised; and not least, why this form of religious practice is so successful all over the world. Though it cannot be claimed that this volume provides exhaustive answers to all of these questions, by promoting a focus on ritual practice it does a very good job at illuminating at least a few, and brings a much-needed microlevel approach to all of them.

The cohesion of the chapters is provided not only by the consensus among the authors that these self-proclaimed antiritualists are indeed engaging in ritualised behaviours, but also by the fact that all the papers emerge from research done with qualitative, ethnographic methods (all the authors are anthropologists or sociologists by profession, with the exception of one theologian). The definition of 'PentecostalCharismatic' in the title, on the other hand, is quite broad; the chapters cover a wide range of charismatic 'types' of Christianity, from Catholics and Evangelicals who have adopted charismatic practices, to prosperity- or faithgospel Christians, to neo-Pentecostalism in general. The geographic range of empirical data is also broad: four chapters are located in North America, two in South America, one each in Sweden, South Korea, Fiji, and Kenya. The practices that are examined include prayer, sermons, testimonies, deliverance 
(exorcism), healing, being 'slain' in the Spirit, the Toronto Blessing, speaking in tongues, singing hymns, dancing and shouting; the contexts in which they are observed include cell group meetings, regular church services and revival meetings.

Contributions by Csordas and Martyn Percy focus on charismatic groups in decline and the concomitant crisis in ritual behaviours. Lindhardt, Jacqueline Ryle, Kelly Chong and Gretchen Pfeil provide ethnographically rich descriptions of the highly embodied and emotional practices of charismatic Christians, whereas Paul Gifford and Simon Coleman focus more on linguistic aspects of worship. Jon Bialecki reminds us that, although the body and language have been dominant research paradigms in recent work, even among experience-oriented Christians, the ideational plane of divine cosmologies can also help explain ritual behaviour, such as the quietly murmured, subtle prayers of deliverance from demons he examines. The fact that this perspective is in the minority in this collection says something about its overall theoretical orientation: Talal Asad is more prominent than Clifford Geertz, Pierre Bourdieu more than Victor Turner. The first and last chapters, by Robbins and David Smilde, respectively, draw on Randall Collins' work on 'interaction ritual chains', again emphasising the importance of bodily copresence and emotions in explaining how and why rituals work. Robbins' essay on the link between ritual activity and the global success of charismatic Christianity presents a compelling argument that is well placed at the beginning of the book: rather than reproducing another version of the narrative that Pentecostalism compensates for losses experienced in the course of modernisation, Robbins claims that it is successful because it has produced transportable rituals that are easily appropriated in local settings and can therefore effectively offer emotional energy or Durkheimian effervescence in exchange for the membership that is the source of institutional stability. For this reason, he argues, understanding Pentecostal ritual is essential to understanding its success, a most welcome change of perspective that will hopefully spark interest in producing many more studies of the kind assembled here.

\section{MONIQUE SCHEER \\ University of Tübingen (Germany)}

\section{Mayer, Danila. 2011. Park youth in Vienna. $A$ contribution to urban anthropology. Wien, Berlin: Lit Verlag. 216 pp. Pb: €29. ISBN 978-3-643-50253-7.}

This publication is an ethnography of youth and adolescents who have claimed their spaces in the parks of Vienna. In the first part of the book the author gives an overview of classical and recent studies of anthropological youth research as well as urban studies and shows their relevance for her field. The second part of the book is the result of several years of research, applied approaches and participant observation of youth groups in public spaces in Vienna. Danila Mayer is a social anthropologist who has worked for several years as a youth worker and has conducted a lot of research, for example, on internet use and on health awareness of adolescents. Above all, her access and positioning in the field for several years, her experiences of streetwork (social work in public spaces) and in crisis intervention enabled her to offer amazing insights. Long-term participant observation, applied approaches, a trusted position for conducting interviews and the opportunity to reflect on the dynamics of change in youth culture over the years, make this study an extraordinary documentation of youth in Vienna.

Most of the youth she is working with in Viennese parks have a poor economic standing and face social exclusion and marginalisation in many ways. Several of the youth families have migrant background, belong to the propertyless urban population and are excluded from social upward mobility. Due to the schooling system in Austria, which the author briefly outlines (p.72f.), where young people are separated at the very early age of 10 into different tracks and where compulsory schooling ends at the age of 15 , the young boys and girls in 
the study face problems in finding an adequate apprenticeship or education. The jobs they obtain are often 'strenuous, low-income, and lack social security', and 'standing in the park' (p. 165) between two precarious jobs is the reality for several of them. In the governmentfunded training they are often confronted only with pseudo-options. Many of them but not all of the park visitors are socially marginalised (p. 83).

The main foci of the study are the processes of group formation, networking and how the adolescents gain access to the open space. Mayer divides them between 'open' groups, which are more fluid, interested in integrating with others, and comprise a variety of views (e.g. gender, language, religion, nationality, politics) and 'closed' groups, which form a 'rigid circle with their members [that] tend to sectarianism (...) often drawing on perceived ethnicity, nationalism, and religion' (p. 92). The spatial division and the gender-related usage of the parks are highlighted. Relevant body styles and consumer-based lifestyles are often markers for the identity of the youth.

Mayer's process-oriented approach gives insights into the fusion and fission as well as the large group formation and long-term relationships of group members, even if some of the former members are now adults and parents. An exploration of fashions and body styles shows interesting outlines of life style and modes of consumption. Fascinating are the insights into the youth culture concerning global music styles and the rapid changes in favourite dance styles. For some of the park kids, performing music and dancing is a way of gaining success and is an option in the unpromising labour market. For those with migratory backgrounds, their relation to the home country of their parents is contested and remigration not really an option.

Mayer follows the young people to youth centres, neighbourhood cafes, shopping malls, discos, internet cafes and participatory community television institutions, and shows how youth workers are companions for their socialisation in parks and urban spaces. The insight into the youths' own perspectives is disturbing: faced with stigmatisation from their schooling and fractured 'careers', they are now pushed to the margins of society without the required social and cultural capital, being forced to show their 'mobility' and 'flexibility'. These outlines are grounded in a thick description of how social exclusion is practised in Vienna.

Several photos depicting the 'world' and urban spaces of the youth give a vivid image of the youth culture, their music and outdoor activities in the parks. More description on the photos' captions would have provided further insights. All in all, this publication is a very impressive anthropological study of youth socialisation in public neighbourhood parks in Vienna.

\section{MARIA SIX-HOHENBALKEN \\ Institute of Social Antbropology, Austrian \\ Academy of Sciences (Austria)}

\section{Moffat, Tina and Tracy Prowse (eds.) 2010. Human diet and nutrition in biocultural per- spective: past meets present. New York and Oxford: Berghahn Books. 282 pp. Hb.: \$95/£55. ISBN 9781845457655.}

This edited volume starts with the premise that although food is fundamental to humankind, the academic fields addressing food, diet and nutrition have worked in silos to the detriment of each other. It takes a biocultural approach to the subject matter, examining human diet and nutrition from prehistoric to contemporary society. The book has three strong points. Firstly, its comprehensive timespan allows one to draw conclusions on how humanity's past affects diet and nutrition today. Secondly, it brings together the whole range of methods and approaches utilised by anthropologists; in this sense, it serves as a nice reminder of the diversity of the discipline and as a 'mini-refresher course' on archaeology and biological anthropology for social and cultural anthropologists.

The book's third strong point is its case-study approach. Rather than giving a broad overview of human nutrition, most chapters are grounded in specific spatial and 
time-bound settings. This allows for interesting in-depth analysis, rather than trite and sweeping statements about 'change in human diets across the ages' too often found in the literature. The first set of chapters takes an evolutionary approach, focusing on diet and brain evolution, child growth in foraging societies and finally providing prehistoric and evolutionary-based insights on infant and young child nutrition. This feeds into the second set of chapters on breastfeeding. Next are two chapters on children and food insecurity in the developing world, including accounts of urbanisation and the nutrition transition in Nepal and responses to a food crisis in Niger. The book then concludes by addressing nutritional factors in growth and disease. The first case here comes from Imperial Rome and looks at childhood growth. The second is a broad examination of bone density from a bioarcheological perspective and the third an overview of current obesity trends in North America.

The volume is certainly an interesting read with broad appeal. However, it does fall short of its overall goals. In the introduction, the editors state that 'throughout history human nutrition has been shaped by politicaleconomic and cultural forces, and in turn food and nutrition can alter the course and direction of human societies' (p. 1). However, with the exception of the chapters on breastfeeding in Gibraltar and on food security in Niger, the political and economic aspects of diet and nutrition are barely addressed in the book. The book also suffers from timeliness: it was written in 2010 and already some of the assertions and statements about obesity are out-of-date with current research, namely the chapters by Leonard et al. and by Katzmarzyk. The latter specifically adds nothing new to the field. I also find it odd that a book where breastfeeding appears as a common theme to nearly all chapters and constitutes the main focus of three contributions makes no mention of the UNICEF/WHO Code of Marketing of Breast-milk Substitutes and only barely touches upon marketing as a contributing factor to breastfeeding rates. It is also unclear as to who its audience is. Although I think that social and cultural anthropologists would benefit by reading such a book, they also may find the 'technical' aspects of the heavily bioarcheological chapters off-putting, as well as the relatively superficial treatment of culture.

Due to the diversity of contributions the book may seem unorganised at times, but overall, I think this works in its favour. This broad appeal means that anthropologists in one sub-field may read something they would not otherwise - and this cross-subdisciplinary thinking is precisely what the editors intended. This makes it a nice contribution to a syllabus for undergraduate or graduate courses in nutritional biology or anthropology, bioarcheology or medical anthropology, rather than a specialist audience.

\section{RACHEL ELIZABETH IRWIN}

Stockholm International Peace Research Institute (Sweden)

Pfaff-Czarnecka Joanna and Gerard Toffin. 2011. The politics of belonging in the Himalayas. Local attachments and boundary dynamics. New Delhi: Sage. 380 pp. Hb.: £45.00. ISBN 978-81-321-0524-4.

Contemporary anthropologists are striving to make sense of a world increasingly realised as being far more complex, esoteric and blurred than was thought of earlier. The neat geopolitical boundaries of the nation-states, most of which came into existence in the postcolonial era, have also posed challenges to the way identities of any kind could be defined (necessity driven by an inherent pre-condition of anthropological work to locate analysis in identifiable entities). The very confinement of the concept of citizenship has brought about contestations, protests and claims to being something or not being something since, as pointed out in this volume, belonging is equally defined by the fact of not belonging. Since post-modern anthropology is taking recourse to methodological concepts that have potential for manipulation and flexibility, an emotional and subjective concept like belonging seems more appropriate than a more formal 
concept like identity. Belonging also contains the notion of performativity and has an implicit reference to process rather than structure.

The Himalayan region has invited immense intellectual investment from a wide range of scholars because of its unique geopolitical, multicultural and environmental variations and historicity that give ample scope for ethnographic studies and a fertile ground for testing various concepts. We see in this volume a wide range of ethnographic situations from national parks to small town court rooms, from social and religious movements to political protests, economic strategies, kinship and rituals, all discussed under the common framework of belongingness. In this sense belonging emerges as a concept of possibilities and an ontological status that relates probably better to actual situations than the earlier concept of identity.

The volume relates belonging to three broad parameters: territory and indigeneity; socio-religious bonding; and commitments and conflicts. However, we find that ethnographically none are exclusive, as indigeneity for example is clearly routed through ritual or religious bonding and practices of exclusion, and may express itself in conflict, while territoriality may influence kinship commitments even it does not define them. A positive feature of this volume is that it has spread itself over the cultural diversity of the Himalayan region, including ethnographies from Nepal, Uttrakhand, Himachal, North-east India, and covers even the reformulation of mountain identities in the plains, like citizenship and belongingness of the Nepalis in Benaras.

The theoretical issues that are most highlighted dissociate ethnicity from essentialist criteria like kinship and territory, shifting instead towards concepts of movement, emplacement and performance. The role of 'Others' in influencing belonging are also discussed, for example, in two complementary papers about mutual belongingness of temples and devotees, evoking both higher order nationalism and individual-level devotion. Belongingness is thus contextualised within larger political and cultural milieus, where both existing and emerging conditions can play significant roles in how people negotiate identities, not only their own but their village, community and clan identity - as we find in ethnographies of Maoist movements in a Nepal village, the constructed identities of the Naga and of the state of Uttarakhand in India.

The Himalayan region provides interesting examples of how religion is constructed and understood by actors, as this region has historically been under the influence of Hinduism, Buddhism and local cosmologies that have incorporated and also influenced the great traditions. The engagement of devotees to the sacred world as well as the manner in which religion can be linked to issues of belongingness, evoking natural and cultural ties, are the subject of several contributions. Emerging issues like environmentalism have also entered into debates and definitions of belonging as papers on national parks indicate. In both India and Nepal, issues of legitimacy of citizenship have been linked to the willingness to engage responsibly with the environment. However, the question of who has the right to define the margins of responsibility may reflect political hierarchy, rather than real engagement. The volume brings to light issues of marginality and the role of existing and changing political hierarchies in over determining the legitimacy of belonging. It also highlights movements and contestations against such impositions.

This is a richly documented volume that is set in the contemporary social and political realities of the Himalayan frontiers. A question sadly left out is the issue of Tibetans' belonging, although Tibet formed a fulcrum for much of the cultural and political development of this region.

\section{SUBHADRA MITRA CHANNA \\ University of Delhi (India)}

Postill, John. 2011. Localizing the Internet: an anthropological account. New York: Berghahn Books. 180 pp. Hb.: \$40.00/ £23.00. ISBN 978-0-85745-197-2.

Postill's account of internet activism in a suburb of Kuala Lumpur, Malaysia is sobering 
reading for anyone who might imagine that such things herald a new dawn for open and fair democracy. Beginning with an ambitious information technology project called Subang Jaya 2005 (SJ2005), Postill offers an entertaining and insightful ethnographic account of key local players and a theoretical roadmap for carrying out something approaching an anthropology of internet-related practices. Postill eschews the concepts of community and networks for making sense of the internet activists with whom he worked. Both concepts, he suggests, misrepresent important aspects of events on the ground (or the internet). Instead, he suggests that studying internet-related activities requires greater precision across space and time. In particular, he invokes a 'field of residential affairs' as a way of identifying activities carried out by a diverse cluster of people who cannot accurately be categorised as a local community or a network. This slightly unwieldy term is used to denote a domain of 'practical endeavour and struggle in which local agents (activists, politicians, councillors, journalists and others) compete and cooperate over matters of concern to local residents' (p. 115). This enabled Postill to deal more meaningfully with the role of internet technologies and communication in practices impacting on local matters.

Malaysia, like some neighbouring countries in the region, has invested heavily in information technologies designed to stimulate economic growth as well as enhance the capacity of governments to both control and respond to the demands of their populations. The experimental initiative that Postill observed in action was designed to act as a test case for the rest of Malaysia. It began with an ambitious set of targets that included highspeed, affordable internet access to all, as well as responsive websites that would accurately reflect public opinion and help the municipal council channel resources where they were most needed. Postill's ethnographic account suggests that information technologies, like every other technology, get implemented in ways that are not independent of local social and cultural contexts. The disappointing outcome of SJ2005 suggests that, while there are clearly some successes, the net result has not been a radical rollout of affordable, high-speed internet access leading to smoothrunning large-scale democratic e-governance. Instead, Postill describes a familiar tale of competing interests at different levels (grassroots, municipal, regional and national), which set the scene for a dissipation of the efforts that might have led to more effective e-government. Postill is careful to point out that SJ2005 is not exactly a failure either, but several of the successes he cites fall into a category that he labels 'banal activism'. Such banal activism has brought about changes to local taxes, waste collection, traffic congestion, school provision or local crime, but, as Postill acknowledges, are not the revolutionary change desired by the anti-globalisation activists in Barcelona (pp. 56-7). It matters to those implicated within the field of residential affairs, however, and Postill needn't remind anthropologists that it is not our job to dismiss what matters to the people with whom we work (even though they often don't agree on what those things might be!).

There is little to disagree with or criticise in Postill's account. He provides an articulate ethnographic account of internet-related activities in a suburb of Malaysia. The book lays out a model of dealing with internetmediated communication in complex social settings. As such, it offers something of an exemplar for what must surely be an increasingly common situation for anthropologists. Those of us who carried out village studies before the information technology explosion of the past 15 years have watched, amazed, as people start to weave internet communications into the complex tapestry of political and economic activities that shape their fields of affairs, be they residential or otherwise. I would, however, perhaps not dispense with the idea of formal networks as Postill does, though he clearly does not do so lightly or dismissively. While he has done an excellent job of describing the scene and theorising the internet and its related activities, I wonder if an additional layer of analysis might fruitfully be generated by a formal network analysis of the various transactions that are observable 
and made concrete by those local practitioners. I would not suggest replacing any part of the book, but I might have enjoyed an additional chapter dealing with formal social networks in precisely the ways that Postill says might limit or blinker the view of 'actual internet practices' (pp. 14-15).

\section{STEPHEN M. LYON}

Durbam University (United Kingdom)

Rao, Ursula. 2010. News as culture. Journalistic practices and the remaking of Indian leadership traditions. New York and Oxford: Berghahn Books. 240 pp. Hb. $\$ 80.00 /$ £47.00. ISBN 978-1-84545-669-6.

India's news press landscape has a long history, reaching back to the late 18 th century, and being closely tied to the process of nation-making as well as the emergence of politicised and controversial public spheres, or 'split publics' (Rajagopal 2001). In this fascinating monograph, anthropologist Ursula Rao presents a detailed and analytically sharp exploration of the field of news production as it spreads across regional and national discourses and networks. With a particular focus on the situation since the turn of the new millennium, Rao's ethnography covers insightful case studies of individual newspapers and press events, the routine of journalistic work in specific urban localities and political as well as commercial networks across the nation, and the different agendas and agents underlining the highly strategic practice of news making. In four chapters, Rao takes the reader into the microcosm of the news press that, as she argues, is a form of cultural production.

The first chapter begins with the vernacular press in Lucknow, the capital of the north Indian state of Uttar Pradesh. The author has accompanied local reporters to study how they navigate in a field of discourses in order to improve their position vis-à-vis local political leaders or to communicate citizens' interests in the urban milieu. A dynamic milieu of work routines, status aspirations and organisational hierarchies is carefully unfolded in which Rao, among other issues, highlights the difference in hierarchies between Hindi and English language newspapers, the first one being knitted along the lines of seniority and privilege, the latter apparently being based on the ideal of 'flat' hierarchies and on-going competition. Both work cultures respond to market liberalisation's pressure to 'perform' and compete, but while the vernacular Hindi paper seems more rooted in local issues, the English-language newspapers represent an elitist perspective, according to Rao. While this chapter suggests a fairly clear line that divides the two, one might wonder whether the borders are not more oscillating. In fact, this is what Rao proposes in the next chapter when she explores how the diversification of the news print market with economic liberalisation pushes the boundaries of elite and vernacular spheres.

The third chapter investigates the making of political news, and the 'cultivation' of networks and contacts to keep them welloiled in order to allow for efficient access, if need arises. Rao traces the manifold ways in which state journalists strategically invest in relations to the political class, and tickles out the social dynamics and tensions that lie underneath the 'printed surface'. The chapter allows for stunning discussions of moral regimes negotiated between notions of 'hot news', political righteousness and professional ethics. Pinpointing well-selected controversies around public interest and sentiment, as well as charismatic leadership, Rao provides the reader with a complex field of different agendas and agents contesting - and requesting - power over media representation and presence in the field of public attention. Most of all, she argues, journalists must be seen as producers of social relations, as brokers of political power and public interests, well aware of their ambivalent position in terms of searching for and providing news.

In yet another chapter, the author traces the nodal points of linkage between journalists and politicians on the national level. What opens up is a 'play' with different concepts of power, entangling the two groups in reciprocal relationships of kinds, with the hope 
of strong and 'suitable' representation. The ethnographic detail of this chapter opens into the performances tailored towards such purposes. This includes the staging of press conferences and politicians' attempts to capture the press' attention and favour. This focus bridges across to the last chapter that investigates the role of highly commercial private undertakings in the shaping of news cultures. Studying strategies of infotainment, argues Rao, brings forward the growing financial dependence of newspapers to privatised infrastructures of newsmaking. These are accompanied by increased pressure on newspapers to perform along the lines of the English-dominated and urbanised middle classes. This pressure spills into political performance according to 'entertaining' news aesthetics. Sahara, a pan-Indian industrial conglomerate from Lucknow, is the ideal case study to elaborate on this. Yet Rao also strengthens the point that commercialisation and critical reporting do not necessarily exclude each other, even though there seems to be an underlining weakening of critical and subversive potential in the news print industry.

Each chapter in this monograph elucidates the rich ethnographic data in the context of a variety of theoretical discussions, ranging from anthropology to media studies, thus making it relevant for readers with a non-regional interest. Rao's work responds well to Arvind Rajagopal's edited volume The Indian Public Sphere (2009). This is definitely a remarkable ethnography about more than 'just' newspaper politics in North India, and a worthwhile read for scholars and students interested in urbanised middle-class discourses, media practice in a variety of local settings in contemporary India.

\section{References}

Rajagopal, A. 2001. Politics after television: religious nationalism and the reshaping of the Indian public. Cambridge: Cambridge University Press.

Rajagopal, A. (ed.) 2009. The Indian public sphere: structure and transformation. Oxford: Oxford University Press.
CHRISTIANE BROSIUS

University of Heidelberg (Germany)

Şaul, Mahir and Ralph A. Austen (eds.) 2010. Viewing African cinema in the twentyfirst century: art films and the Nollywood video revolution. Athens, OH: Ohio University Press. 248 pp. Pb.: \$26.95. ISBN 9780821419311.

Viewing African Cinema is poised on the cusp of the millennium, looking back to reassess the initial decades of African cinema while laying out new directions for future study. The volume seeks to bring disparate discourses and domains of analysis into connection, bridging the divide between art house or auteurist African film and more popular video works from Nollywood and beyond. The text also attempts to move beyond established oppositions between humanists and social scientists, film aesthetics and social analysis, production and reception, and Francophone and Anglophone spheres; most of the essays challenge these conventions, opening up new possibilities for analysis.

The initial section on Nollywood offers both critical reassessments and fresh agendas. Jonathan Haynes argues that film studies can bring a new seriousness to Nollywood, including archival collection and preservation of video, auteurist analyses of directors, and attention to genre. Whether this really represents the best way forward remains an open question; jettisoning interdisciplinary ethnographic and cultural studies approaches for more canonical film studies treatments would hardly constitute an improvement. Onookome Okome articulates the postcolonial anxieties underlying resistance to the Nollywood phenomenon. Within the universities and critical circles, elite cultural mediators seek to present a certain face of Nigeria to the world and reject popular video as sensationalist, reactionary or embarrassing: misleading the masses or misrepresenting Africa. But as Okome cogently shows, while Nollywood doesn't conform to cultural nationalist or Pan-Africanist agendas of what the people 'should' like, video certainly engages the politics of the present, local-global 
processes and urban conditions in ways that are deeply meaningful to a very large public within Nigeria and beyond. Ignoring or denigrating these trends serves little purpose.

Stark oppositions between art film and video are consistently undermined in the essays. Echoing some of Okome's themes, Birgit Meyers argues that Ghanaian video was shaped not in competition with FESPACO art cinema, but rather in the face of competing discourses from the state and the national film industry. Even as their power and productivity were declining, bureaucrats and industry insiders still sought to determine what could and could not be shown on screen - arguing that film must have an uplifting or educational aim, even as video was taking over a privatised and commercialised public sphere. In this contested domain, where issues of market and morality, aesthetics and authority are very much at stake, Meyers never seeks to simply celebrate the popular; instead, she historicises and contextualises the rise of video, arguing against critiques 'grounded in a paternalistic, if not colonial, idea of cinema as a medium for education and enlightenment' (p. 57).

Nollywood, of course, is shorthand for a complex transnational phenomenon, and the volume treats its diverse manifestations in different sites, starting with Abdulla Uba Adamu's rich discussion of Hausa videos, moral narratives, gender and the public/private dialectics of social space. The collection also opens up new ground by following Nigerian video to East Africa, as Matthias Krings traces a crucial moment of emergence, as West African video imports gave way to a vigorous homegrown industry in Dar es Salaam known as Bongowood (he also explores diverse media practices of translation such as video dubbing and the photo-novel). Krings's piece is one of a trio of works on Tanzania that can be read in conjunction. In keeping with the volume's title, Laura Fair foregrounds issues of reception, beautifully exploring the (nostalgic?) memories of Tanzanian cinema-goers from the 1950s on, foregrounding the pleasures they derived from Hindi film: emotional investments with the struggles of downtrodden heroes, keen interest in the performance of dance and popular music, and a delight in spectacular entertainments. Bryce's piece, on the other hand, is rather more limited, discussing just two films as examples of a Tanzanian film industry that never came into existence. Much of her discussion pertains to a narrow window of time in the 1990s and has been largely outpaced by more recent developments in Bongo video and the film festival circuit.

Historical analysis and critical reevaluation figure prominently in several other essays. Mahir Saul rethinks the critical orthodoxy on Francophone African cinema, rejecting its narrow categorisation as necessarily 'political' and didactic in intent. As he shows, early African cinema was far more diverse than it has been labelled, as directors sought (but often failed to win) a popular audience and commercial success, often limited by constraining regional markets. Similarly challenging boundaries between 'politics' and 'commerce', Stefan Sereda places FESPACO film and Igbo videos in a common analytic frame, examining how strategies of 'cautionary pedagogy' operate in different registers. And, at the end, Lindsey Green-Simms offers a lovely take on cultural technologies of modernity and mobility, linking the evolution of motion pictures and the motor car in West Africa - as vehicles of images and subjects of them from Sembene to Nnebue.

All the essays are not equally successful. Peter Rist's case for the statistical analysis of film shot-length fails to convince, producing results that hardly seem worth the effort. And while there is an interesting piece on the history of California Newsreel, this points to a larger problem: certainly a volume on African spectatorship should include a much broader consideration of circuits of distribution in Africa, the USA, Europe and Asia. Similarly, the changing conditions of reception receive little attention, as the decline of cinema halls and rise of broadband downloading are touched on, but barely discussed. The burgeoning African film festival circuit on the continent, in Europe, Latin America and the USA is neglected, with the rise of festivals in Durban, Burundi, Rwanda, Nairobi and Uganda never even mentioned; FESPACO 
hardly stands alone these days. And while Șaul mentions the topic, the increasing importance of South Africa as a centre of film production and circulation is surprisingly absent, along with Kenya - in the last two years of ZIFF, these countries have swept the awards, along with offering M-Net and the first Kiswahili movie channel on the continent. What this indicates, more than anything else, is the rapid pace of innovation and change in film and media practices on the continent, and the way that developments on the ground are far outpacing the capacity to capture them in any single volume.

WILLIAM BISSELL

Lafayette College (USA)

Werbner, Richard. 2011. Holy hustlers, schism, and prophecy. Apostolic reformation in Botswana. Berkeley and Los Angeles: University of California Press. 268 pp. Pb: $\$ 24.95$, £16.95. ISBN 9780520268548. Includes DVD.

Holy Hustlers, Schism, and Prophecy includes a DVD with a similarly titled documentary, released in 2009. In the introduction to the book, Werbner tells us that it is important to begin by watching the film, and only then moving to the remainder of the book (p. 3). This exercise, the author proposes, will inaugurate a cinematic experience that will be extremely helpful for the intellectual absorption of his description.

Indeed, with the induction produced by the screening, upon reading Holy Hustlers I felt like embarking on a sensuous journey, marked by a profusion of colours, objects, movements and ambiences, populated by stories of healing, disruption, transformation, schism and serendipity. This is also explained by Werbner's writing style; he deliberately chooses to avoid extensive conceptual debates, citations and long footnotes, engaging instead in handpicked comparative ethnography (with Engelke 2007 and Klaits 2010, for instance) and focusing on detailed, engaging description and interpretation. The result is, as Werbner expected, a cinematic book speaking to and from episodes that are also portrayed in the film.

This book is far more than an authored account by a renowned and experienced anthropologist who masters ethnographic description but is also concerned with the epistemological implications of a multi-layered field methodology. It is an extremely relevant, stateof the-art portrait of contemporary African Christianity through the scope of some of its most distinctive features: schism, creativity, prophecy and power. From this perspective, it offers, through the central figures of Bishop Boitshepelo and other younger prophets who dwell in the Apostolic Eloyi and Conollius churches, a portrait of the moral crises and opportunities in contemporary Botswana and southern Africa. It is also somewhat of a culmination of Werbner's research engagement with religion in Botswana, highlighted in his earlier works, in documentaries like Seance Reflections with Richard Werbner (2004), Shade Seekers and the Mixer (2006) and Encountering Eloyi (2008), and various papers and articles. This sense of culmination is illustrated by the way the author stands as someone 'naturally' inserted in that context in both book and film. The final scene of the film, when Werbner stands in the middle of the church service holding his recorder to the face of the prophet in the middle of an act of exorcism, is telling.

Rather than following the structure of the book, I will focus here on two particular moments that happen to be portrayed in the film too. Both are emblematic because they capture the powerful interplay of image and word that Werbner puts together so skilfully in Holy Hustlers. The first moment depicts a consultation between the prophet and believer/client/ill person. Werbner's camera stands at the door, while prophet Matthew and prophet Andrew sit on a bed and engage in a funny, heart-warming dialogue between each other and with the patient (p. 142 and ff.). In the meantime, a negotiation takes place where the prophetic imagination devises and identifies the malady. The dialectic character of the healing session, focused around attempts to visualise, interpret and define (recognise) the 
'problem' is proof of what Werbner describes as a new regime or modality of religious agency and power in Gaborone (the 'holy hustlers'), which is conducive of schism between stances of orthodoxy and individuality, patrimony and innovation. Here, a new regime of religious experience is exposed, one that ultimately led to a schism among the Apostolic community in Botswana's capital - a creative, charismatic mode that clashes with a particular orthodox tradition, marked by a dramatic tone, given the clash between father and sons that mediates it.

The second moment reveals a man, prophet Matthew, sitting down among debris in the space of what used to be a church, torn down to ruins by a storm the night before (p. 121 and ff.). A churchgoer arrives and heads to a basin where the holy water used to be kept. But now the church is destroyed, and the believer has his doubts regarding the water's holiness. Prophet Matthew contests and exerts his emerging authority upon the man, who reluctantly accepts that the water is blessed because prophet Matthew says so. He does it, but not without wittingly ranting about the prophet's personality on his way out. Here we perceive the 'eventual' character of Werbner's ethnography, how he brilliantly captures and incorporates serendipity that affects faith and the constant (street smart) negotiation of authority between specialist and patient, leader and follower, prophet and believer.

If I were to choose a common theme for the book and film, it would be the notion of crisis and turmoil, in the sense of creativity and transformation rather than disaster and deprivation. This disruption is played out in several stances: rural/urban distinctions, generational ruptures and iconoclasms, liturgical divergences, institutional excisions, etc. This is perhaps why Holy Hustlers ends with a somewhat revelatory conclusion: what began as a mere ethnography of Apostolic reformation in Botswana turns out to be a debate on the dianoia and noesis behind the multilayered register adopted by Werbner. There is a certain continuity within the complex intellectual, discursive and aesthetic displays captured by Werbner and the political disruptions that emerge from them. For this reason, I believe this book deserves far more than just an Africanist or religious studies readership. It is a fascinating read for any anthropologist, regardless of expertise.

\section{References}

Engelke, M. 2007. A problem of presence. Beyond scripture in an African church. Berkeley, CA: University of California Press.

Klaits, F. 2010. Death in a church of life. Moral passion during Botswana's time of AIDS. Berkeley, CA: University of California Press.

\section{RUY LLERA BLANES}

University of Lisbon (Portugal)

London School of Economics (UK) 